\title{
BMJ Open School staff perpetration of physical violence against students in Uganda: a multilevel analysis of risk factors
}

\author{
Katherine G Merrill, ${ }^{1}$ Louise Knight, ${ }^{1}$ Judith R Glynn, ${ }^{2}$ Elizabeth Allen, ${ }^{3}$ \\ Dipak Naker, ${ }^{4}$ Karen M Devries ${ }^{1}$
}

To cite: Merrill KG, Knight L, Glynn JR, et al. School staff perpetration of physical violence against students in Uganda: a multilevel analysis of risk factors. BMJ Open 2017;7:e015567. doi:10.1136/ bmjopen-2016-015567

- Prepublication history and additional material are available. To view please visit the journal online (http://dx.doi.org/10. 1136/bmjopen-2016-015567)

Received 14 December 2016 Revised 20 March 2017 Accepted 6 April 2017

CrossMark

${ }^{1}$ Department of Global Health and Development, London School of Hygiene and Tropical Medicine, London, UK ${ }^{2}$ Department of Infectious Disease Epidemiology, London School of Hygiene and Tropical Medicine, London, UK

${ }^{3}$ Department of Medical Statistics, London School of Hygiene and Tropical Medicine, London, UK

${ }^{4}$ Raising Voices, Kampala, Uganda

Correspondence to Katherine G Merrill; kgmerrill1@gmail.com

\section{ABSTRACT}

Objective To conduct a multilevel analysis of risk factors for physical violence perpetration by school staff against Ugandan students.

Design Multilevel logistic regression analysis of crosssectional survey data from 499 staff and 828 caregivers of students at 38 primary schools, collected in 2012 and 2014 during the Good Schools Study.

Setting Luwero District, Uganda.

Main outcome measure Past-week use of physical violence by school staff against students was measured using the International Society for the Prevention of Child Abuse and Neglect 'Child Abuse Screening Tool- Child International' and the WHO Multi-Country Study on Women's Health and Domestic Violence against Women. Results Of 499 staff, 215 (43\%) reported perpetration of physical violence against students in the past week. Individual risk factors associated with physical violence perpetration included being a teacher versus another type of staff member $(p<0.001)$, approving of physical discipline practices $(p<0.001)$, having children $(p<0.01)$, being age $30-39$ years $(p<0.05)$, using physical violence against non-students $(p<0.05)$ and being a victim of intimate partner violence (IPV) $(p<0.05)$. We observed weak evidence $(p=0.06)$ that male staff members who had been a victim of IPV showed higher odds of violence perpetration compared with male staff who had not been a victim of IPV. No evidence was observed for school- or community-level risk factors.

Conclusions Physical violence perpetration from school staff is widespread, and interventions are needed to address this issue. Staff who have been victims of violence and who use violence against people other than students may benefit from additional interventions. Researchers should further investigate how school and community contexts influence staff's physical violence usage, given a lack of associations observed in this study.

\section{INTRODUCTION}

The perpetration of physical violence by school staff against students is increasingly recognised as a serious public health concern. ${ }^{1}$ In national surveys, over $40 \%$ of young adults in Kenya ${ }^{2}$ and over $50 \%$ of children in Tanzania ${ }^{3}$ report having experienced physical violence from school staff before age

\section{Strengths and limitations of this study}

- This is one of the first studies to investigate risk factors for school staff perpetration of physical violence against students from the perpetrator's as opposed to victim's perspective, using crosssectional data from a low-income setting.

- Whereas existing studies have often considered individual-level risk factors, this study adopts a multilevel approach to explore risk factors at the school and community in addition to the individual levels.

- The study was cross-sectional, limiting inference about the direction of observed effects.

- Measures used may not have fully captured the constructs we sought to describe, despite piloting of survey items and good internal consistency of composite measures.

18. Figures are higher in Luwero District, Uganda, where $93 \%$ of primary school students report ever being victims of physical violence from school staff. ${ }^{4}$ Although prevalence estimates typically rely on child reports of experience, self-reported figures from staff about their perpetration are similarly high. ${ }^{56}$

Data on predictors of staff's physical violence perpetration against students are scarce, particularly in low- and middle-income countries. Importantly, we identified only a small number of studies that have considered risk factors from the perspective of the staff member as perpetrator as opposed to the student as victim, ${ }^{5-9}$ although determinants are likely to differ for perpetration and victimisation. Studies that have done so are limited to the United States, ${ }^{79}$ Israel $^{56}$ and Cyprus. ${ }^{8}$ We found no such studies conducted in Africa. Moreover, studies have rarely considered risk factors beyond the individual level, used multilevel modelling techniques or employed a conceptual framework to guide analyses.

Filling these gaps is necessary to inform prevention efforts seeking to 
curb staff-perpetrated violence and reduce adverse consequences for children by working directly with perpetrators. We conducted a multilevel analysis using cross-sectional data collected in 2012 and 2014 during the Good Schools Study, ${ }^{10}$ a cluster-randomised trial of an intervention seeking to prevent violence against children in Ugandan schools. At the time of data collection, corporal punishment in schools had been banned by the Ugandan Ministry of Education and Sports since 1997 but was not explicitly prohibited by law. ${ }^{11}$ Our aim was to investigate multilevel predictors of school staff physical violence perpetration.

\section{METHODS}

\section{Study design, setting and data collection}

Baseline data were collected from staff at 42 primary schools in Luwero District, Uganda, from June to July 2012, with analysis restricted to 38 schools to align with data collected from caregivers at endline. The staff survey was developed and refined over 3 months prior to administration and translated into Luganda, the local language. Following review by a panel of teachers and Raising Voices staff, the survey was piloted among 20 Kampala primary school staff to test comprehension and clarity and again among 40 staff to test item distribution and refine study procedures. A research team conducted the survey through individual interviews and programmed answers into phones or tablets. All researchers spoke Luganda and received 3 weeks of advance training on non-judgemental and confidential ways of interviewing and collecting data.

We additionally incorporated endline data collected from students' caregivers (ie, parents/guardians) at 38 of the 42 schools in June-July 2014, following intervention delivery. Caregiver data were not collected at baseline and were not collected from 4 of the 42 schools at endline, since these were boarding as opposed to day schools. Caregivers were invited to participate through letters distributed to students 3 days prior. Female caregivers were invited first and, if unavailable, were replaced by another caregiver. Items from the staff survey were adapted for use in the caregiver survey, which was piloted for length and wording among caregivers in Kampala schools. Study methods are published in full elsewhere. ${ }^{412}$

Composed of both urban and rural areas, Luwero District has an estimated population of 433100 people, of whom $60 \%$ are below 18 years of age. Luwero is similar demographically to other parts of Uganda. The district possesses an equal sex ratio and a mean household size of 4.4 persons. As of 2002, roughly three-quarters of people were literate and had access to safe water, two-thirds of households used subsistence farming methods and the vast majority of households used firewood and charcoal for cooking. ${ }^{10}$

Based on enrolment listings, 151 eligible schools in Luwero were grouped into three strata according to their student sex ratio: more than $60 \%$ girls, more than $60 \%$ boys or approximately even. The strata were designed to achieve a reasonable balance between treatment groups for the trial from which our data came. Eligible schools contained $79.7 \%$ of primary 5,6 and 7 students in Luwero. Forty-two schools were randomly selected proportional to the stratum size, and all agreed to participate. All staff members and primary caregivers of primary 7 students were invited. Individual written consent was obtained.

\section{Hierarchical conceptual framework and hypotheses}

Benbenishty and Astor's heuristic mode ${ }^{13}$ views school violence as resulting from factors operating directly and indirectly within nested contexts. School factors lie at the model's centre. While developed to explain student victimisation, the model can be applied to others involved in school violence, including staff. ${ }^{13}$ We drew from the model in distinguishing three risk factor groupings, which we term 'individual' (eg, staff characteristics), 'school' (eg, perceived school climate) and 'community' (eg, school neighbourhood characteristics).

We hypothesised that staff physical violence perpetration would result from a combination of individual, school and community factors, operating directly and indirectly (figure 1). We conceptualised community factors and staff's background characteristics as most distal, followed by school factors, with staff's individual attitudes as most proximate. Our analysis centred on direct pathways.

Regarding individual factors, the literature suggests links between experiencing one form of violence and perpetrating another. ${ }^{14}$ We therefore hypothesised that a staff member's experience of sexual abuse as a child, intimate partner violence and non-partner sexual violence would be associated with increased likelihood of physical violence perpetration against students. We anticipated that staff who use violence against non-students would be more likely to use violence against students, based on studies showing that individuals who perpetrate violence tend to do so on multiple occasions and in different contexts. ${ }^{16}{ }^{17}$ We expected staff who personally approve of use of violence to show greater likelihood of perpetrating violence, given that teachers' attitudes have been correlated with their use of violence in the limited existing literature on risk factors for teacher violence perpetration. ${ }^{56}$ We drew from literature on parental use of corporal punishment in hypothesising that staff of younger age $\mathrm{e}^{18}$ and with fewer financial resources, ${ }^{19}$ larger numbers of offspring, ${ }^{20}$ less education ${ }^{21} 22$ and poorer mental health ${ }^{23}$ would perpetrate more physical violence against students. We did not develop a priori hypotheses regarding the predicted direction of effect for a staff member's sex, job title, ethnicity, religion, years worked at the school or relationship status, given that evidence was either conflicting ${ }^{5-7}$ or absent in the literature.

Regarding school factors, we hypothesised that staff would use more physical violence in schools in which social norms were more accepting of physical discipline practices and in which a negative sense of school climate prevailed. Social norms, distinct from personal 
attitudes, refer to the views and behaviours that are thought to be typical or acceptable among members of a community. Perceived social norms can constrain individuals' behaviour, given that lack of conformity can result in social ostracising. ${ }^{24}$ In the literature, social norms tolerant of violence within classrooms and schools have been linked with the occurrence of violence in some school settings. ${ }^{2526}$ Negative perceptions of school climate-referring to the quality and character of the school environment ${ }^{13}$ - when aggregated by school have further been correlated with student victimisation and bullying in schools. ${ }^{132}$

Turning to community factors, we predicted that social norms tolerant of physical discipline practices as well as lower socioeconomic status (SES) in communities surrounding schools would be associated with more use of physical discipline by school staff. Norms that are more accepting of physical discipline practices have been linked to the occurrence of corporal punishment in schools in Israeli $^{13}$ and Korean ${ }^{28}$ contexts. Lower SES of students' families has further been associated with higher student reports of violence from teachers. ${ }^{29} 30$

\section{Outcome variable}

In line with the trial analysis for the Good Schools Study, ${ }^{12}$ our outcome variable drew from standardised, internationally recognised measures. Staff were classified as having committed physical violence if reporting having committed one or more behavioural act of violence (eg, slapping, caning) against a student within the past week, based on 22 items (see online supplementary appendix 1). Items were adapted from the International Society for the Prevention of Child Abuse and Neglect 'Child Abuse Screening Tool-Child Institutional ${ }^{31}$ and the WHO Multi-Country Study on Women's Health and Domestic Violence against Women. ${ }^{32}$

\section{Risk factors}

Individual

A staff member's sex and whether they were Baganda (the region's most common tribe) were modelled as binary variables, while job at school, highest qualification obtained, religion, relationship status and number of offspring were modelled as categorical. Staff's SES was measured using three categorical variables, considered independently given an insufficient number of variables to create an index: housing status, number of adults sleeping in the same area and number of meals eaten yesterday.

The 20-item Self-Report Questionnaire (SRQ) screening instrument was used to assess staff members' mental health. The instrument's reliability and validity have been established elsewhere. ${ }^{33}$ In our study, Cronbach's alpha- the most widely used measure of reliability-was 0.70 , indicating good internal consistency. Given a lack of validated cut-off in Uganda, we coded the top 30\% of the distribution as having a 'high' score, indicating probable depression or anxiety. We chose this cut-point based on previous analyses of a multicountry study employing SRQ data, in which the use of validated cut-points across a range of countries classified $30 \%$ of women on average as probable depression/anxiety cases. ${ }^{34}$

We assessed whether a staff member had ever been a victim of intimate partner violence (six items on physical, sexual or emotional violence), child sexual abuse (two items) or non-partner sexual violence (two items). One variable assessed staff physical violence perpetration against non-students. These variables, constructed as binary, were developed using measures from the WHO Multi-Country Study on Women's Health and Domestic Violence against Women. ${ }^{32}$ Number of years worked at the school was modelled as categorical.

We generated three composite measures of staff attitudes: (1) a 6-item measure assessing attitudes

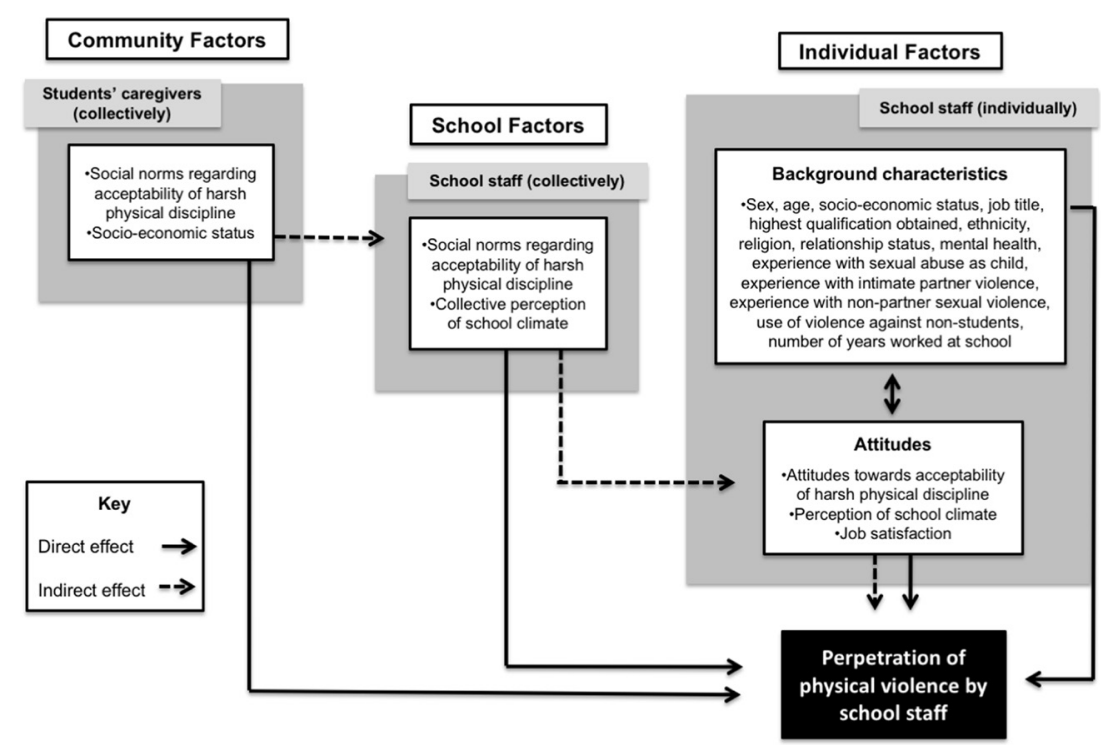

Figure 1 Hierarchical conceptual framework depicting hypothesised direct and indirect pathways through which risk factors influence school staff perpetration of physical violence in Luwero District, Uganda. 
toward physical discipline (Cronbach's alpha 0.75), (2) a 16-item measure assessing school climate (Cronbach's alpha 0.75 ) and (3) a 5-item measure assessing job satisfaction (Cronbach's alpha 0.65). Scores were assigned to each response option, and mean scores were calculated. Staff responding to less than $50 \%$ of items were coded as missing. Where more than $50 \%$ of items were answered, missing items were replaced by the individual's mean score on remaining items. Response distributions were divided into thirds.

\section{School}

We measured social norms at the school level-that is, the extent to which staff perceived other staff members to approve or disapprove of physical discipline practicesby aggregating staff attitudes toward discipline by school. A mean score was derived. Other studies have aggregated responses by classroom or school to approximate social norms. ${ }^{27}{ }^{35}$ Additionally, as a proxy for school climate, staff members' responses to the school climate measure were aggregated by school, and a mean score was derived.

\section{Community}

To approximate social norms in communities surrounding schools, we generated composite measures using caregiver data. We aggregated items assessing caregivers' own views on physical discipline to approximate perceived approval or disapproval of such practices among those external to the school. Items pertained to physical discipline practices in school and at home. Caregiver scores were aggregated by school.

We aggregated data on the SES of students' families to consider effects of a school community's SES on staffs' physical violence perpetration, as in studies on student violence victimisation. ${ }^{13} 27$ We generated an SES index using principal component analysis, a technique for reducing variables to fewer dimensions. ${ }^{36}$ Scores were divided into thirds. See online supplementary appendices 2 and 3 for detail on variables generated.

\section{Statistical analyses}

Data comprised a two-level hierarchical structure. Staff were clustered by school (ie, each staff member was associated with only one school). We conceived of caregivers for students at a given school as forming part of a 'community' for that particular school. Given that each caregiver was associated with only one school and that we aggregated caregiver reports by school, caregiver data were analysed at the same level as the school. Our analysis therefore required a random effect only at the school level.

Using STATA 13, we employed multilevel logistic regression analysis of risk factors, including a random effect at the school level to account for clustering. We estimated univariate associations followed by multivariate associations, fitting distal then proximal factors. The basic model (model 1) included community factors and staff background characteristics. We added school variables in model 2 and then staff individual attitudes in model 3. Risk factors were only adjusted for variables hypothesised to be higher in the hierarchy (ie, more distal) to avoid overadjustment for factors potentially on the causal pathway. ${ }^{37}$

A forward stepwise approach was used to determine staff background characteristics to include in model 1. Variables with the strongest crude effect were added first. We retained characteristics that notably improved the logistic regression model $(\mathrm{ie}, \mathrm{p}<0.10)$ when more proximal factors were added. Based on our conceptual framework (figure 1), we included all community factors in model 1, all school factors in model 2 and all staff individual attitude factors in model 3 . Sex and age, considered a priori confounders, were included in all models. Given the presence of normal and binomial distributions in a random-effects logistic regression model, the reliability of estimates in each model was statistically checked, confirming that the quadrature was accurately approximating the likelihood. ${ }^{38}$ We examined collinearity between variables by checking for large changes in the standard errors of the regression coefficients between univariate and multivariate models. We used the likelihood ratio test to examine the final model for notable interactions between all exposure variables.

\section{RESULTS}

Of all 645 staff at the 42 selected schools, 577 (89\%) completed baseline surveys. Staff from four boarding schools ( $\mathrm{n}=78$ staff) were excluded, since no caregiver data were collected at these schools. In total, data on 499 staff from 38 schools were analysed, with a median of 24 staff per school (IQR 13-34; full range 6-50). Very little missing data were observed on staff variables (table 1 ).

Of 1258 caregivers of primary 7 students at the 38 schools, $828(66 \%)$ completed endline surveys, with a median of 22 caregivers per school (IQR 12-30; full range 1-42). All respondents were included in the social norms measure, and little missing data were observed when building the SES index.

\section{Study population}

Of 499 staff, 215 (43.1\%) reported having perpetrated physical violence against students in the past week. The sample included a slightly higher proportion of female $(58.3 \%)$ than male $(41.7 \%)$ staff (table 1$)$. Most were teachers $(79.4 \%)$. Just over $40 \%$ reported having ever experienced intimate partner violence $(45 \%$ female, $35 \%$ male). A majority (75.0\%) had worked at the school for 5 or more years.

\section{Risk factors}

In univariate analysis (table 1), staff background characteristics that positively correlated with physical violence perpetration included age group $(\mathrm{p}<0.01)$, being a teacher versus another type of staff member $(p<0.001)$, having children $(p<0.001)$, having ever been a victim of intimate partner violence $(\mathrm{p}<0.01)$, having ever used physical violence against non-students $(\mathrm{p}<0.05)$ and having worked 
Table 1 Univariate associations between risk factors and perpetration of physical violence by school staff against students in the past week in Luwero District, Uganda ( $\mathrm{n}=499$ staff)

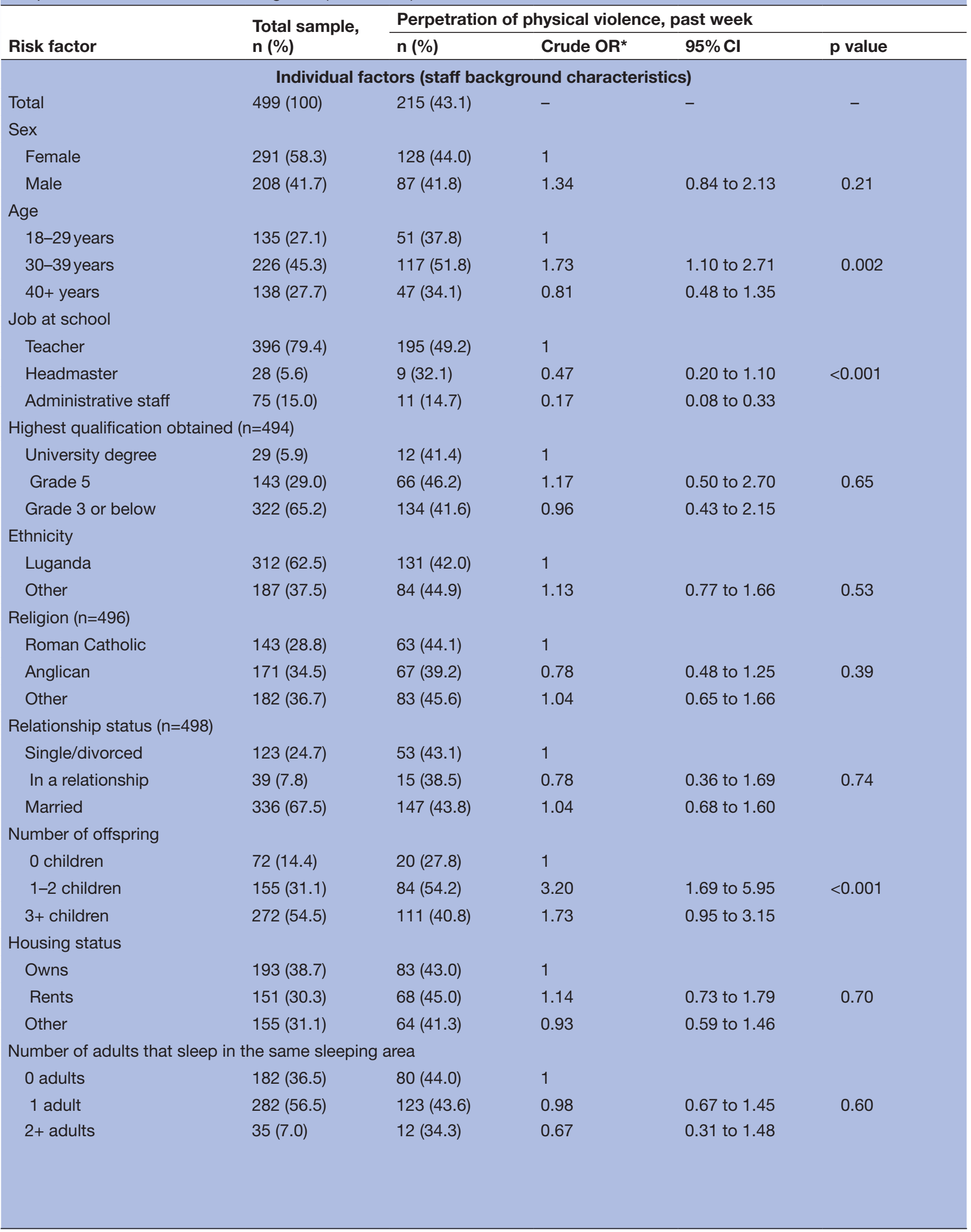


Table 1 Continued

\begin{tabular}{|c|c|c|c|c|c|}
\hline \multirow[b]{2}{*}{ Risk factor } & \multirow{2}{*}{$\begin{array}{l}\text { Total sample, } \\
\text { n (\%) }\end{array}$} & \multicolumn{4}{|c|}{ Perpetration of physical violence, past week } \\
\hline & & n (\%) & Crude OR $^{*}$ & $95 \% \mathrm{Cl}$ & p value \\
\hline \multicolumn{6}{|c|}{ Number of meals eaten yesterday } \\
\hline 1 meal & $42(8.4)$ & $17(40.5)$ & 1 & & \\
\hline 2 meals & $156(31.3)$ & $68(43.6)$ & 1.14 & 0.56 to 2.32 & 0.92 \\
\hline $3+$ meals & $301(60.3)$ & $130(43.2)$ & 1.15 & 0.59 to 2.27 & \\
\hline \multicolumn{6}{|c|}{ Mental health distress } \\
\hline Low & $332(66.5)$ & $136(41.0)$ & 1 & & \\
\hline High & $167(33.5)$ & 79 (47.3) & 1.29 & 0.87 to 1.90 & 0.20 \\
\hline \multicolumn{6}{|c|}{ Victim of child sexual abuse } \\
\hline No & $472(94.6)$ & $207(43.9)$ & 1 & & \\
\hline Yes & $27(5.4)$ & $8(29.6)$ & 0.48 & 0.20 to 1.16 & 0.10 \\
\hline \multicolumn{6}{|c|}{ Victim of intimate partner violence } \\
\hline No & $295(59.1)$ & $110(37.3)$ & 1 & & \\
\hline Yes & $204(40.9)$ & $105(51.5)$ & 1.71 & 1.17 to 2.50 & 0.006 \\
\hline \multicolumn{6}{|c|}{ Victim of non-partner sexual violence } \\
\hline No & $450(90.2)$ & $193(42.9)$ & 1 & & \\
\hline Yes & $49(9.8)$ & $22(44.9)$ & 1.00 & 0.54 to 1.87 & 0.99 \\
\hline \multicolumn{6}{|c|}{ Use of violence against non-students } \\
\hline No & $443(88.8)$ & $182(41.1)$ & 1 & & \\
\hline Yes & $56(11.2)$ & $33(58.9)$ & 1.96 & 1.08 to 3.58 & 0.03 \\
\hline \multicolumn{6}{|c|}{ Number of years worked at school $(n=498)$} \\
\hline $0-2$ years & $52(10.4)$ & $15(28.9)$ & 1 & & \\
\hline $3-4$ years & $72(14.4)$ & $26(36.1)$ & 1.46 & 0.66 to 3.21 & 0.04 \\
\hline $5+$ years & $374(75.0)$ & $174(46.5)$ & 2.15 & 1.11 to 4.14 & \\
\hline
\end{tabular}

\section{Community factors}

Social norms accepting of physical discipline within community

\begin{tabular}{|c|c|c|c|c|c|}
\hline Low & $176(35.3)$ & 73 (46.5) & 1 & & \\
\hline Medium & 159 (31.9) & $70(42.4)$ & 0.87 & 0.49 to 1.53 & 0.70 \\
\hline High & $164(32.9)$ & $72(40.7)$ & 0.79 & 0.46 to 1.36 & \\
\hline \multicolumn{6}{|c|}{ Socioeconomic status } \\
\hline High & $173(34.7)$ & $70(40.5)$ & 1 & & \\
\hline Medium & $171(34.3)$ & $72(42.1)$ & 1.06 & 0.61 to 1.84 & 0.68 \\
\hline Low & $155(31.1)$ & $73(47.1)$ & 1.27 & 0.72 to 2.22 & \\
\hline
\end{tabular}

\section{School factors}

Social norms accepting of physical discipline among school staff

$\begin{array}{lccccc}\text { Low } & 169(33.9) & 65(42.5) & 1 & & \\ \text { Medium } & 180(36.1) & 76(44.4) & 1.08 & 0.61 \text { to } 1.87 & 0.97 \\ \text { High } & 150(30.1) & 74(42.3) & 1.02 & 0.58 \text { to } 1.80 & \\ \begin{array}{l}\text { Perceived quality of school climate (aggregated by school) } \\ \text { High }\end{array} & 164(32.9) & 62(37.8) & 1 & & \\ \text { Medium } & 167(33.5) & 84(50.3) & 1.65 & 0.97 \text { to } 2.81 & 0.14 \\ \text { Low } & 168(33.7) & 69(41.1) & 1.13 & 0.66 \text { to } 1.93 & \end{array}$




\begin{tabular}{|c|c|c|c|c|c|}
\hline \multirow[b]{2}{*}{ Risk factor } & \multirow{2}{*}{$\begin{array}{l}\text { Total sample, } \\
\text { n (\%) }\end{array}$} & \multicolumn{4}{|c|}{ Perpetration of physical violence, past week } \\
\hline & & n (\%) & Crude OR* & $95 \% \mathrm{Cl}$ & p value \\
\hline \multicolumn{6}{|c|}{ Personal acceptance of physical discipline } \\
\hline Low & $222(45.3)$ & $54(39.4)$ & 1 & & \\
\hline High & $162(32.5)$ & $106(49.8)$ & 1.63 & 1.02 to 2.61 & \\
\hline \multicolumn{6}{|c|}{ Perceived quality of school climate $(n=498)$} \\
\hline High & $147(29.5)$ & $64(43.5)$ & 1 & & \\
\hline Medium & $164(32.9)$ & $69(42.1)$ & 0.93 & 0.58 to 1.48 & 0.92 \\
\hline Medium & 159 (31.9) & 73 (45.9) & 1.43 & 0.90 to 2.26 & 0.23 \\
\hline Low & $174(34.9)$ & $79(45.4)$ & 1.40 & 0.89 to 2.21 & \\
\hline
\end{tabular}

${ }^{*}$ Assessed via logistic regression with a random effect at the school level to account for clustering. $p$ values derived from likelihood ratio tests. Missing data excluded.

at the school for more years $(\mathrm{p}<0.05)$. Those with higher levels of mental health distress showed slightly higher odds of physical violence perpetration (crude OR 1.29), but this association did not reach statistical significance. Staff with high acceptance of physical discipline were more likely to report violence perpetration $(\mathrm{p}<0.05)$. No associations were observed for individual-level SES variables or for any community or school risk factors.

In multivariate analysis (table 2), after controlling for staff background characteristics and community factors in model 1, significant associations remained for age category $(p<0.05)$, job at school $(p<0.001)$, having children $(p<0.01)$, having been a victim of intimate partner violence $(p<0.05)$ and having ever used physical violence against non-students $(p<0.05)$. While lacking significance in univariate analysis, having ever been abused as a child became associated with lower likelihood of physical violence perpetration $(\mathrm{p}<0.01)$ after adjusting for job at school, number of offspring and intimate partner violence victimisation. Crude evidence for number of years worked at the school disappeared.

No associations were observed for any community-level factors in model 1 or any school-level factors in model 2. Staff highly accepting of physical discipline had greater odds of violence perpetration $(\mathrm{p}<0.001)$ in model 3. No evidence of collinearity was observed.

Weak evidence of interaction was observed between a staff member's sex and having ever been a victim of intimate partner violence $(\mathrm{p}=0.06)$ (table 3$)$. After stratifying by sex, male staff who reported having ever been a victim of intimate partner violence showed 2.56 times the odds of physical violence perpetration compared with male staff who reported never having been a victim of intimate partner violence (95\% CI 1.29 to 5.09).

\section{DISCUSSION}

\section{Summary of main findings}

In this multilevel analysis, we investigated individual, school and community risk factors of school staff's physical violence perpetration against students in Luwero District, Uganda. At the individual level, staff who were teachers as opposed to another type of staff member and who personally approved of physical discipline practices were at particular risk for perpetrating physical violence against students. Having children, having used violence against non-students, having been a victim of intimate partner violence and being age 30-39 were also associated with increased odds of perpetration. However, we found weak evidence that the association between having perpetrated physical violence and having been a victim of intimate partner violence varied by sex, whereby male staff who had experienced intimate partner violence showed higher odds of violence perpetration compared with male staff who had not experienced intimate partner violence, but the association for females did not reach significance. We found no evidence for any school- or community-level factors.

\section{Comparison with other study findings}

Our findings for use of physical violence against non-students as well as students are consistent with literature on the links between committing physical violence across multiple settings. Studies show, for example, that men committing physical violence outside the home are more likely to perpetrate partner or non-partner violence. ${ }^{16}{ }^{17}$ The association observed between intimate partner violence victimisation and physical violence perpetration against students should be considered alongside evidence of links between intimate partner violence victimisation and perpetration. ${ }^{14}{ }^{15}$ In our 
Table 2 Multivariate associations between risk factors and perpetration of physical violence by school staff against students in the past week in Luwero District, Uganda ( $n=497$ staff)

\begin{tabular}{|c|c|c|c|}
\hline Risk factors & Adjusted OR & $95 \% \mathrm{Cl}$ & $\mathrm{p}$ value \\
\hline \multicolumn{4}{|c|}{ Individual factors (staff background characteristics)* } \\
\hline \multicolumn{4}{|l|}{ Sex } \\
\hline Female & 1 & & \\
\hline Male & 1.08 & 0.72 to 1.61 & 0.73 \\
\hline \multicolumn{4}{|l|}{ Age } \\
\hline 18-29years & 1 & & \\
\hline 30-39years & 1.75 & 1.04 to 2.95 & 0.04 \\
\hline $40+$ years & 1.09 & 0.57 to 2.08 & \\
\hline \multicolumn{4}{|l|}{ Job at school } \\
\hline Teacher & 1 & & \\
\hline Headmaster & 0.55 & 0.23 to 1.36 & $<0.001$ \\
\hline Administrative staff & 0.17 & 0.08 to 0.34 & \\
\hline \multicolumn{4}{|l|}{ Number of offspring } \\
\hline 0 children & 1 & & \\
\hline $1-2$ children & 2.65 & 1.35 to 5.19 & 0.006 \\
\hline $3+$ children & 1.52 & 0.75 to 3.05 & \\
\hline \multicolumn{4}{|c|}{ Victim of child sexual abuse } \\
\hline No & 1 & & \\
\hline Yes & 0.34 & 0.13 to 0.85 & 0.02 \\
\hline \multicolumn{4}{|c|}{ Victim of intimate partner violence } \\
\hline No & 1 & & \\
\hline Yes & 1.61 & 1.05 to 2.45 & 0.03 \\
\hline \multicolumn{4}{|c|}{ Use of violence against non-students } \\
\hline No & 1 & & \\
\hline Yes & 2.23 & 1.11 to 4.47 & 0.02 \\
\hline \multicolumn{4}{|c|}{ Community factors ${ }^{*}$} \\
\hline \multicolumn{4}{|c|}{$\begin{array}{l}\text { Social norms accepting of physical discipline } \\
\text { within community }\end{array}$} \\
\hline Low & 1 & & \\
\hline Medium & 0.93 & 0.54 to 1.62 & 0.81 \\
\hline High & 0.84 & 0.49 to 1.43 & \\
\hline \multicolumn{4}{|l|}{ Socioeconomic status } \\
\hline High & 1 & & \\
\hline Medium & 1.18 & 0.68 to 2.07 & 0.75 \\
\hline Low & 1.23 & 0.70 to 2.15 & \\
\hline \multicolumn{4}{|c|}{ School factors $†$} \\
\hline \multicolumn{4}{|c|}{$\begin{array}{l}\text { Social norms accepting of physical discipline } \\
\text { among school staff }\end{array}$} \\
\hline Low & 1 & & \\
\hline Medium & 1.28 & 0.74 to 2.21 & 0.67 \\
\hline High & 1.14 & 0.66 to 2.97 & \\
\hline \multicolumn{4}{|c|}{ Perceived quality of school climate } \\
\hline High & 1 & & \\
\hline Medium & 1.47 & 0.82 to 2.63 & 0.37 \\
\hline Low & 1.06 & 0.61 to 1.84 & \\
\hline
\end{tabular}




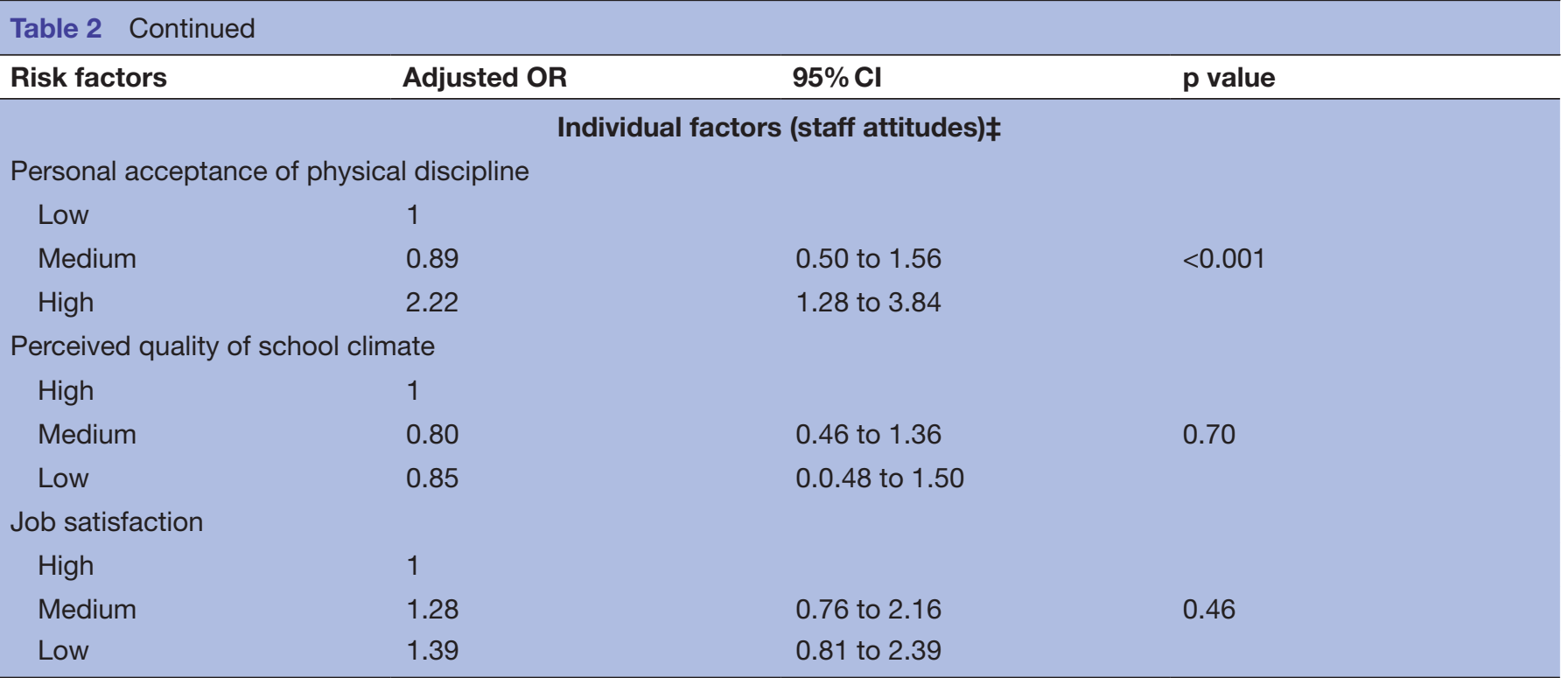

All analysis conducted using logistic regression with a random effect at the school level to account for clustering. $p$ values derived from likelihood ratio tests. Missing data excluded.

${ }^{*}$ Adjusted for staff background characteristics and community factors only (model 1).

†Adjusted for staff background characteristics, community factors and school factors (model 2).

$\ddagger$ Adjusted for staff background characteristics, community factors, school factors and staff attitudes (model 3).

study, a greater proportion of female staff had ever been a victim of intimate partner violence than male staff. We found weak evidence for statistical interaction between intimate partner violence and a staff member's sex, which supports findings from other studies indicating that men and women who have experienced intimate partner violence may show different tendencies for perpetrating violence. ${ }^{1417}$ Although we did not measure a staff member's perpetration of intimate partner violence, our results may be partially replicating the finding that those who perpetrate violence against one group may do so against another. Taken together, these results suggest that individuals who are prone to using physical violence as a means of resolving conflict in one setting are likely to use it in other settings, including against students.

Unexpectedly, given evidence on associations between experiencing one form of violence and perpetrating another, ${ }^{17} 39$ we found no evidence for staff members' sexual victimisation from non-partners and found a negative association with child sexual abuse victimisation. These results may relate to sample size considerations, as less than $10 \%$ of staff reported experiencing non-partner sexual violence and only $5.4 \%$ reported childhood sexual abuse.

Findings that an individual's attitudes are associated with likelihood of perpetration are consistent with existing studies on teacher violence perpetration, ${ }^{56}$ corporal punishment from parents ${ }^{40}$ and youth aggression in school. ${ }^{41}$ Psychological theories, such as the reasoned action approach, ${ }^{42}$ highlight the influence of attitudes on behaviour. Teachers' greater contact time with students or perceived role as the authority figure at school could explain their higher risk of perpetration compared with other staff. Staff with children of their own may customarily use forms of physical discipline at home and thus show higher odds of perpetration against students at school compared with staff without children. In contrast to literature on corporal punishment from parents, which shows younger age as associated with greater

Table 3 Adjusted estimates of the OR for perpetration of physical violence against students in the past week and victimisation of intimate partner violence (IPV) in Luwero District, stratified by staff members' sex

\begin{tabular}{clllr}
\hline \multirow{2}{*}{ Stratified by sex } & Victim of IPV & $\begin{array}{l}\text { Perpetrated physical violence } \\
\text { against students, } \mathbf{n}(\%)\end{array}$ & $\begin{array}{l}\text { Stratum-specific } \\
\text { adjusted OR* }\end{array}$ & $\begin{array}{l}\text { 95\% Cl } \\
\text { p value }\end{array}$ \\
\hline Female & No & $65(40.1)$ & 1 & 0.66 to 1.97 \\
& Yes & $63(47.7)$ & 1.14 & 0.06 \\
Male & No & $45(33.1)$ & 1 & 1.29 to 5.09 \\
& Yes & $42(58.3)$ & 2.56 & \\
\hline
\end{tabular}

Adjusted ORs and $95 \%$ Cls for the association between physical violence perpetration and sex and IPV, respectively, assessed using logistic regression with a random effect at the school level to account for clustering; $p$ value derived from the likelihood ratio test.

*Adjusted for all staff background characteristics (age, job at school, number of offspring, victimisation of child sexual abuse, use of violence against non-students) and community-level factors (social norms accepting of physical discipline within community and socioeconomic status). 
likelihood of perpetration, ${ }^{18}$ we found that the middle age category (ages 30-39) showed the highest odds. As in other studies on teacher violence perpetration, we found no associations with the staff member's sex. ${ }^{58}$ We also failed to find an association for mental health, although parents with poorer mental health employ corporal punishment more often. ${ }^{23}$

Our lack of findings for social norms at the school or community levels is unexpected, particularly given the strong association observed for staff members' personal acceptance of physical discipline practices. Other studies have shown evidence for a link between social norms at the school level and youth's physical aggression ${ }^{25}{ }^{26}$ as well as the occurrence of corporal punishment in school. ${ }^{28} 29$ Outside of the school setting, studies have shown social norms to be strongly correlated with parents' attitudes toward the acceptability of corporal punishment ${ }^{43}$ and men's perpetration of sexual violence. ${ }^{44}$ We also failed to find an association between perceptions of school climate-either at the individual or school level-and staff members' physical violence perpetration. In contrast, other studies have found that negative perceptions of school climate are linked with students' victimisation of violence. ${ }^{1327}$ While these null findings could reflect deficiencies in our measurement tools, they also likely reflect broader complexities behind accurately measuring norms and perceptions.

\section{Study strengths and limitations}

This study offers one of the first multilevel investigations of school staff use of physical violence against students from the perspective of the staff members themselves as perpetrators. Our study included a large representative sample of Luwero District schools, and 100\% of schools invited agreed to participate. Our findings may be generalisable to other districts in Uganda which possess a similar socio-demographic profile as the Luwero District. However, given this study's cross-sectional nature, conclusions cannot be drawn regarding the direction of observed effects. Our study is limited in measuring violence perpetration through use of a self-reported measure, although this measure is standardised and widely employed internationally. ${ }^{31} 32$ Although survey items were piloted and composite measures demonstrated good internal consistency, our measures may not have fully captured the constructs we sought to describe. A staff member's own response was included when aggregating composite measures by school, perhaps mixing individual and school effects in cases with few staff per school. While data collectors were thoroughly trained, some social desirability bias could have occurred. Although under-reporting would typically be of concern, staff reports of perpetration were high and compatible with student reports of victimisation (52\% reported having experienced physical violence in the past week). ${ }^{4}$ Bias may further have resulted from the $66 \%$ caregiver response rate; caregivers with lower SES or greater tolerance of discipline may have been less likely to participate, perhaps weakening effects observed. While caregiver data were collected at endline, not baseline, the intervention centred on promoting change within the immediate school context, and minimal bias is likely. Sample size restrictions prevented separate investigations by sex or job title.

\section{Implications and future research}

Our findings suggest that interventions which address staff's own experiences of violence and which target staff who use physical violence against others in addition to students may help reduce staff-perpetrated physical violence against students. Relatively small numbers of staff in Ugandan schools have great influence over students in their classrooms. Interventions supporting staff to use less violence are likely to have a knock-on positive effect for students as well as staff themselves.

Several interventions, including the Incredible Years Program $^{45}$ and the Irie Classroom Toolbox ${ }^{46}$ as well as the Good Schools Toolkit, ${ }^{10}$ seek to reduce teacher-perpetrated violence. Whereas existing programmes are typically available to all school staff, our findings indicate potential value in offering additional support to those who have been exposed to violence or who use violence outside school. We are unaware of programmes that consider teachers' characteristics to develop tailored messaging on alternative discipline approaches. Future research should further investigate how school and community contexts influence staff use of physical violence over time, given a lack of evidence for an effect in our study.

Acknowledgements The authors would like to thank all Raising Voices staff and the Good Schools implementation team.

Contributors KGM and KMD conceived of the analysis question. KGM conducted the analysis, led data interpretation and drafted the manuscript. LK, JRG and EA contributed to the analysis plan and data interpretation. DN developed the Good Schools intervention, obtained funding and contributed to data interpretation. KMD contributed to the analysis plan and data interpretation and served as the principal Investigator of the Good Schools Study. All authors provided input on the manuscript write-up and approved the final manuscript.

Funding This work was funded by the MRC/DfID/Wellcome Trust via the Joint Global Health Trials Scheme (to KMD) and the Hewlett Foundation and the Oak Foundation (to DN).

Competing interests DN developed the Good School Toolkit. This article reports on analyses of baseline and endline surveys from a trial evaluating the Toolkit. No other authors have any competing interests to report.

Ethics approval The study was approved by the London School of Hygiene and Tropical Medicine Ethics Committee (6183) and the Uganda National Council for Science and Technology (SS2520). All staff and caregivers provided individual written consent.

Provenance and peer review Not commissioned; externally peer reviewed.

Data sharing statement № additional data are available.

Open Access This is an Open Access article distributed in accordance with the Creative Commons Attribution Non Commercial (CC BY-NC 4.0) license, which permits others to distribute, remix, adapt, build upon this work non-commercially, and license their derivative works on different terms, provided the original work is properly cited and the use is non-commercial. See: http://creativecommons.org/ licenses/by-nc/4.0/

(C) Article author(s) (or their employer(s) unless otherwise stated in the text of the article) 2017. All rights reserved. No commercial use is permitted unless otherwise expressly granted. 


\section{REFERENCES}

1. Pinheiro P. World Report on Violence against Children. United Nations Secretary-General's Study on Violence against Children 2006.

2. UNICEF. Violence against Children in Kenya: findings from a 2010 National Survey. Nairobi, Kenya: Division of Violence Prevention, National Center for Injury Prevention and Control, 2012.

3. UNICEF. Violence against Children in Tanzania: findings from a National Survey 2009. Dar es Salaam, Tanzania: Multi Sector Task Force on Violence Against Children, 2011.

4. Devries KM, Child JC, Allen E, et al. School violence, mental health, and educational performance in Uganda. Pediatrics 2014;133:e12 9-e137.

5. Khoury-Kassabri M. The relationship between teacher self-efficacy and violence toward students as mediated by teacher's attitude. Soc Work Res 2012;36:127-39.

6. Khoury-Kassabri M, Attar-Schwartz S, Zur H. The likelihood of using corporal punishment by kindergarten teachers: the role of parent-teacher partnership, attitudes, and religiosity. Child Indic Res 2014;7:369-86.

7. Rust JO, Kinnard KQ. Personality characteristics of the users of corporal punishment in the schools. J Sch Psychol 1983;21:91-8.

8. Theoklitou D, Kabitsis N, Kabitsi A. Physical and emotional abuse of primary school children by teachers. Child Abuse Negl 2012;36:64-70.

9. Tremlow SW, Fonagy P, Sacco FC, et al. Teachers who bully students: a hidden trauma. Int J Soc Psychiatry 2006;52:187-98.

10. Devries KM, Allen E, Child JC, et al. The Good Schools Toolkit to prevent violence against children in Ugandan primary schools: study protocol for a cluster randomised controlled trial. Trials 2013;14:232-9.

11. The Republic of Uganda, UNICEF \& Raising voices. Creating safer schools: alternatives to corporal punishment. 2012.

12. Devries KM, Knight L, Child JC, et al. The Good School Toolkit for reducing physical violence from school staff to primary schoo students: a cluster-randomised controlled trial in Uganda. Lancet Glob Health 2015;3:e378-e386.

13. Benbenishty R, Astor A. School Violence embedded in Context. Oxford, UK: Oxford University Press, 2005.

14. Stith SM, Smith DB, Penn CE, et al. Intimate partner physical abuse perpetration and victimization risk factors: a meta-analytic review. Aggress Violent Behav 2004;10:65-98.

15. Palmetto N, Davidson LL, Breitbart V, et al. Predictors of physical intimate partner violence in the lives of young women: victimization, perpetration, and bidirectional violence. Violence Vict 2013;28:103-21.

16. Abrahams N, Jewkes R, Hoffman M, et al. Sexual violence against intimate partners in Cape Town: prevalence and risk factors reported by men. Bull World Health Organ 2004;82:330-7.

17. Jewkes R, Fulu E, Roselli T, et al. Prevalence of and factors associated with non-partner rape perpetration: findings from the UN Multi-country Cross-sectional study on men and violence in Asia and the Pacific. Lancet Glob Health 2013;1:e208-e218.

18. Straus M, Moynihan M, eds. Who spanks the most? New York, NY: Lexington Books, 1994

19. Dietz TL. Disciplining children: characteristics associated with the use of corporal punishment. Child Abuse Negl 2000;24:1529-42.

20. Youssef RM, Attia MS, Kamel MI. Children experiencing violence. I: parental use of corporal punishment. Child Abuse Negl 1998;22:959-73.

21. Eamon MK. Antecedents and socioemotional consequences of physical punishment on children in two-parent families. Child Abuse Negl 2001;25:787-802.

22. Youssef RM, Attia MS, Kamel MI. Children experiencing violence. II: prevalence and determinants of corporal punishment in schools. Child Abuse Negl 1998;22:975-85.

23. Hunter WM, Jain D, Sadowski LS, et al. Risk factors for severe child discipline practices in rural India. J Pediatr Psychol 2000;25:435-47.

24. Lapinski MK, Rimal RN. An explication of social norms. Communication Theory 2005;15:127-47.
25. Henry DB, Farrell AD, Schoeny ME, et al. Influence of school-level variables on aggression and associated attitudes of middle school students. J Sch Psychol 2011;49:481-503.

26. Saarento S, Kärnä A, Hodges EV, et al. Student-, classroomand school-level risk factors for victimization. J Sch Psychol 2013;51:421-34.

27. Khoury-Kassabri M, Benbenishty R, Astor RA, et al. The contributions of community, family, and school variables to student victimization. Am J Community Psychol 2004;34:187-204.

28. Kim DH, Kim KI, Park YC, et al. Children's experience of violence in China and Korea: a transcultural study. Child Abuse Negl 2000;24:1163-73.

29. Benbenishty R, Zeira A, Astor RA. Children's reports of emotional, physical and sexual maltreatment by educational staff in Israel. Child Abuse Negl 2002;26:763-82.

30. Khoury-Kassabri M. Student victimization by educational staff in Israel. Child Abuse Negl 2006;30:691-707.

31. ICAST-C: The ISPCAN Child Abuse Screening Tool-Child Version. Manual and Proposed Guidlines for Pilot Administration. Aurora, CO: International Society for the Prevention of Child Abuse and Neglect, 2006.

32. Garcia-Moreno C, Ellsberg H, Heise M, et al. World Health Organization (WHO) Multi-Country Study on Womens' Health and Domestic Violence against Women. Geneva, Switzerland: World Health Organization, 2005.

33. Beusenberg C, Orley J. A User's Guide to the Self-Reporting Questionnaire (SRQ). Geneva, Switzerland: World Health Organization, 1994.

34. Devries K, Watts C, Yoshihama M, et al. Violence against women is strongly associated with suicide attempts: evidence from the WHO multi-country study on women's health and domestic violence against women. Soc Sci Med 2011;73:79-86.

35. Pozzoli T, Gini G, Vieno A. The role of individual correlates and class norms in defending and passive bystanding behavior in bullying: a multilevel analysis. Child Dev 2012;83:1917-31.

36. Vyas S, Kumaranayake L. Constructing socio-economic status indices: how to use principal components analysis. Health Policy Plan 2006;21:459-68.

37. Victora CG, Huttly SR, Fuchs SC, et al. The role of conceptual frameworks in epidemiological analysis: a hierarchical approach. Int J Epidemiol 1997;26:224-7.

38. StataCorp. Stata 13 Base Reference Manual. College Station, Texas: Stata Press, 2013

39. Manchikanti Gómez A. Testing the cycle of violence hypothesis: child abuse and adolescent dating violence as predictors of intimate partner violence in young adulthood. Youth Soc 2011;43:171-92.

40. Vittrup B, Holden GW, Buck J. Attitudes predict the use of physical punishment: a prospective study of the emergence of disciplinary practices. Pediatrics 2006;117:2055-64.

41. Chen JK, Avi Astor R. School violence in Taiwan: examining how western risk factors predict school violence in an asian culture. $J$ Interpers Violence 2010;25:1388-410.

42. Fishbein M, Ajzen I. Predicting and changing behavior: the reasoned Action Approach. New York: Psychology Press, 2010.

43. Taylor CA, Hamvas L, Rice J, et al. Perceived social norms, expectations, and attitudes toward corporal punishment among an urban community sample of parents. J Urban Health 2011;88:254-69.

44. Shannon K, Leiter K, Phaladze N, et al. Gender inequity norms are associated with increased male-perpetrated rape and sexual risks for HIV infection in Botswana and Swaziland. PLoS One 2012;7:e28739-8.

45. Baker-Henningham $\mathrm{H}$, Walker $\mathrm{S}$, Powell $\mathrm{C}$, et al. A pilot study of the incredible years teacher training programme and a curriculum unit on social and emotional skills in community pre-schools in Jamaica. Child Care Health Dev 2009;35:624-31.

46. Baker-Henningham $\mathrm{H}$, Vera-Hernández $\mathrm{M}$, Alderman $\mathrm{H}$, et al. Irie Classroom Toolbox: a study protocol for a cluster-randomised trial of a universal violence prevention programme in Jamaican preschools. BMJ Open 2016;6:e012166. 